of vessels with the food which they contained. After each trial the position of the vessels was changed and they were grouped differently. Associations connecting the size of the receptacles with their contents were established with greater difficulty because the monkeys were tempted to choose the largest vessel, as if they thought it ought to contain the greatest quantity of food. All of the experiments showed that movements ill-adapted to success were progressively eliminated, while movements well adapted took place more frequently, and each time with more certainty.

WASHINGTON UNIVERSTTY, ST. LOUTS.

$$
\text { Thomas Furlong, Jr. }
$$

\title{
EXPERIENCE AND REALITY.
}

Pure Experience and Reality. Evander Bradley McGilvary. Philos. Rev., rgo7, XVI., 266-2 84 .

A tenable system of philosophy must be compatible with scientific facts. The philosophers of pure experience, postulating as they do that the real is the immediately experienced, feel in duty bound to set themselves right with science which deals with realities purporting to exist prior to experience. Professor James reconciles his experiential philosophy with science by tacitly admitting the existence of a genuine reality which is not necessarily experienced. Professor Dewey attempts the reconciliation by allowing the existence of a something 'non-contemporaneously experienced.' But inasmuch as the cornerstone of his system is the theory that the condition of all reality is contemporaneous cognitive experience, this preexperiential something cannot have complete reality. The scientist, however, in his statement of the nature of his objects, asserts their reality, ignoring the experience which conditions that reality; but he does so, Professor Dewey contends, only because he is not concerned with their 'extrascientific features,' and because the experience factor is so unavoidably there in experience. This contention of Professor Dewey involves a serious confusion. That experience is necessary for the recognition of scientific reality is a fact which the scientist does not ignore. The telescope, for example, testifies to the astronomer's acceptance of this truth. But the preëxperiential object of the scientist stands in no need of a contemporaneous cognitive experience to make it real, and when Professor Dewey makes this assertion the scientist not only ignores it but rightly treats it as a gross assumption. ${ }^{1}$ The object exists

${ }^{\prime}$ Cf. Professor Dewey's 'Disclaimer,' Philos. Rez., x9o7, XVI., 4ro-422. 
as a complete reality, independent of the mutations in any single experience.

An examination of the theory of representative knowledge gives the answer to the question, how can a reality, existing prior to experience, become an object of subsequent experience of it? We have subjective images or ideas which represent previously experienced realities, present realities not immediately experienced, past and future realities which have and have not become objects of our immediate experience. These representative images bear a direct reference to the transsubjective realities, and we come to know the reality through the image.

WEILESLEY COLXEGE.

HeLen G. Hood.

\section{MONISM.}

Les objections au monisme. F. LE Dantec. Revue Philosophique, LXII., x I 4-1 35 .

Quoting the statement of one who, in religious matters, had persistently maintained the attitude of a free-thinker yet who had sought to transcend the doctrines of materialism and positivism on the ground that they were not sufficiently comforting, the author says that nearly all of the objections to monism spring from analogous considerations. 'They are based on what Ribot calls ' the logic of sentiment.'

The monism which the author supports he first strips of all metaphysical implications. To hold a monistic conception of the world it is not necessary to reduce all phenomena to unity; monism is rather a formula. This formula maintains that nothing transpires which can be recognized by man which does not involve transformations which are susceptible of measurement. 'Susceptibility of measurement' is made the watchword of the monism which the author regards as a recent acquisition of human thought. This monism is not to be identified with the materialism of the ancients.

The dualism to which this monism is opposed is clearly stated by Pasteur, who says that " in each of us there are two men: the man of wisdom, who by observation, experimentation, and reason, hopes to arrive at a knowledge of nature, and the man of tradition, the sensitive man, the man of faith or of doubt, the man of sentiment, the man who does not wish to die but who believes that his essential nature will live on."

This dualism admits the existence of immutable entities that act without being themselves modified and to these immutable entities the 